\title{
NATUREZA, INDIVIDUAÇÃO E LOGOS EM MERLEAU-PONTY
}

\author{
Osvaldo Fontes Filho*
}

SÍNTESE - Este estudo sintetiza as leituras de Merleu-Ponty sobre a ciência moderna, e procura esclarecer como elas desautorizam uma concepção determinista da Natureza. Ao contrário da física newtoniana e de outras ontologias substancialistas, que submetem a contingência ao entendimento, Merleau-Ponty desvela um registro

do descontínuo, onde os seres reduzem-se a "feixe de probabilidades". Assim, ao fornecer sentido ontológico ao polimorfismo do tempo e do espaço percebidos, Merleau-Ponty intercepta em teóricos pós-newtonianos renovada concepção da matéria: "éter dos acontecimentos", ela se esclarece menos pelas longas cadeias causais que pela "pululação ilimitada das categorias". A conseqüente refutação dos princípios de identidade é oportunidade para investir individualidades em devir e modos de existência ubiqüitários, atestados pelas modernas embriologias, elementos que ajudam a reformular o cenário ontológico. PALAVRAS-CHAVE - Natureza. Ciência. Acontecimento. Individualidade. Ontologia.
ABSTRACT - This paper summarizes MerleauPonty lectures about modern sciences and tries to enlighten how he disavows a determinist conception of Nature. Adversely to Newtonian physics and others substantialistic ontologies that translate contingency into understanding, MerleauPonty reveals a register of discontinuity in Nature where beings amount to be a "bundle.of probabilities". Therefore, in getting ontological sense to the polymorphism of perceived time and space, Merleau-Ponty identifies in post- Newtonian theorists a renewed conception of matter as "ether of events". Matter do not have to be shaped by long causal chains but by "unlimited profusion of categories". A consequent refusal of identity principles is an opportunity to a close examination of individualities in progress and ubiquitous ways of existence, both attested by moderns embryologies. In doing so, Merleau-Ponty aims to reformulate ontological scene.

KEY WORDS - Nature, science, event, individuality, ontology.

O que se acreditava ingenuamente o ser, aparece como fato, acaso, num fluxo, caso particular em história mais geral.

Merleau-Ponty. Notes de Cours

\footnotetext{
* Departamento de Filosofia da Pontifícia Universidade Católica de São Paulo.
} osvaldofontes@itelefonica.com.br

\begin{tabular}{|l|l|l|l|l|l|}
\hline VERITAS & Porto Alegre & v. 51 & n. 2 & Junho 2006 & p. 37-54 \\
\hline
\end{tabular}


Nos cursos que ministrou entre 1956 e 1960 no Collège de France, MerleauPonty procurou desautorizar a noção de Natureza proveniente das ciências naturais, isto é, como "o conjunto dos objetos dos sentidos", para entendê-la como matriz do tempo e do espaço, isto é, como a camada originária onde os seres mantêm uma relação de reciprocidade ou de co-pertença. O que exige interrogá-la de seu interior, na invocação da experiência como "fundamento último de direito" (Merleau-Ponty 1960, p. 227). Todo o empenho de Merleau-Ponty consiste, pois, em mostrar a ancoragem corporal do espírito como contrafação da presença a si do pensamento. Para tanto, lança-se a uma exaustiva revisão da metafísica da presença - pura, plena, sem sobra, absoluta -, e de seu usual sistema de oposições - essência/aparência, inteligível/sensível, alma/corpo -, todas dependentes da oposição do originário e do derivado. Merleau-Ponty julga que, uma vez questionado esse sistema de dualidades, o caminho abre-se para a retomada da interrogação husserliana acerca do pensamento absoluto: Natureza ou Espírito? Uma terceira dimensão, como se sabe, é chamada a se impor, a do Ser bruto ou selvagem, dimensão onde o natural e o espiritual reúnem-se na indistinção.

Visto que somos na junção da Natureza, do corpo, da alma e da consciência filosófica, visto que a vivemos, não podemos conceber um problema cuja solução não esteja esboçada em nós e no espetáculo do mundo, deve haver neles um meio para compor em nosso pensamento aquilo que em nossa vida forma um bloco (Merleau-Ponty 1960, p. 223-224).

Portanto, duplo é o interesse em revisar o conceito de Natureza. Por um lado, estender em profundidade o campo da fenomenologia, para abarcar aquilo que em nós resiste à fenomenologia, qual seja, o ser natural. Se o campo transcendental deixa de se restringir aos pensamentos "para se tornar o da experiência inteira", compreendê-lo por dentro equivaleria a igualar a reflexão ao que normalmente fazemos transitando do mundo da Natureza ao mundo do espírito, da atitude natural às atitudes artificiais. Significaria, ainda, prestar conta das mutações da intencionalidade em decorrência das indivisões do ser - Merleau-Ponty mesmo se pergunta (1960, p. 224): "qual é essa 'interioridade' que será capaz das próprias relações do interior com o exterior?" Por fim, Merleau-Ponty entende desenvolver, a partir de uma Natureza concebida como "meio humano da História", uma análise do corpo como expressão simbólica, com o que re-fundar filosoficamente a história da humanidade enquanto história de uma "comunidade ideal do sujeito encarnado" (1968: 109 e 115, respectivamente). Ao cabo dessa dupla investigação, é uma "nova ontologia" que o filósofo entende viabilizar.

A particular situação na qual a reflexão merleau-pontiana entende se colocar, interna às junturas constitutivas da "experiência inteira", explica porque é o filósofo e não o historiador das ciências que se interroga sobre a Natureza. A filosofia "habita a história e a vida, mas ela gostaria de se instalar em seu centro, no ponto onde elas são advento, sentido nascente" (1960, p. 225). Uma vez evocada tal cumplicidade, o objetivo não poderia ser outro senão resgatar de toda abstração: 
Entre a suficiência e a capitulação [face aos cientistas], falta encontrar para os filósofos a atitude justa. Ela consistiria em perguntar à ciência não o que é o ser (a ciência calcula no ser, seu procedimento constante é supor conhecido o desconhecido), mas o que seguramente ele não é, em entrar na crítica científica das noções comuns aquém da qual a filosofia, hipoteticamente, não saberia se estabelecer (Merleau-Ponty 1968, p. 118-119).

Uma renovada filosofia da Natureza tanto mais se legítima quando são consideradas todas aquelas "construções abstratas" resultantes de uma acepção objetivista da Natureza. Mesmo porque, lembra Merleau-Ponty, "todo naturalismo posto à parte, uma ontologia que passa sob silêncio a Natureza fecha-se no incorporal e dá, por isso mesmo, uma imagem fantástica do homem, do espírito e da história" (1968, p. 91). Tal é confirmado pelas doutrinas marxistas: a mais célebre das filosofias da história, ajuíza Merleau-Ponty, repousa sobre um conceito absoluto da atividade objetiva, conceito deixado inquestionado e, consequentemente, tornado mítico. Como é mítica grande parte da ciência que, originada no cartesianismo, constrói-se na afirmação de uma ordem imutável regida por princípios de causalidade ou de finalidade (cf. 1995, p. 120).

Se o filósofo que se atém à ciência moderna a fim de saber o que é a Natureza conclui por tomá-la como um Englobante - por sobre as ruínas do Objeto -, é porque ele é ali instado a desautorizar uma concepção determinista da necessidade intra-mundana, sinônimo de ontologia cartesiana (cf. 1995, p. 124). A Natureza é menos "parceiro da consciência no face a face do conhecimento" que "objeto donde nós surgimos" (1968, p. 94). Ela aponta, pois, para uma relação originária do homem e do ser que não é aquela do para-si ao em-si. Relação anterior ao sersujeito e ao ser-objeto, ela desconcerta e desorienta o pensamento reflexivo.

[Do ser primordial] a nós não há derivação e quebra; ele não tem nem a textura cerrada de um mecanismo, nem a transparência de um todo anterior às suas partes; não se pode conceber nem que ele se engendra a si mesmo, o que o faria infinito, nem que seja engendrado por um outro, o que o traria à condição de produto e de resultado morto (Merleau-Ponty 1968, p. 95).

Ao procurar sintomas de uma nova consciência da Natureza (e das articulações da experiência que ela revela), o balanço que Merleau-Ponty faz das diferentes tradições de pensamento constata a persistência de uma tensão ontológica que a metafísica cartesiana ajuda a esclarecer. Esta "constrange todo ser, se é intenção que ele seja algo, a ser plenamente, sem lacuna, sem possibilidade escondida [...] sem restrição, infinito ou causa de si” (1968, p. 99). É porque a acepção do ser natural como objeto coloca-o diante da alternativa do nada possível que a Natureza é concebida como derivação dos atributos de um ser infinito: ela somente emerge do nada por sua plenitude de ser $^{1}$. Falar de uma "causa de si" sig-

Já se lia na Phénoménologie de la perception (1945, p. 55): "La connexion de l'essence et de l'existence n'est pas trouvée dans l'expérience, mais dans l'idée de l'infini. Il est donc vrai en fin de compte que l'analyse réflexive repose toute entière sur une idée dogmatique de l'être et qu'en ce sens elle n'est pas une prise de conscience achevée". 
nifica evocar um "Deus efeito que, como todo efeito, necessita ser sustentado por sua causa, sem a qual não seria". Não há, portanto, lacuna que não esteja de antemão garantida de ser colmatada pelo entendimento. De modo que, "quando [os homens] se põem a pensar, o jogo já está feito: para pensar é preciso ser" (1968, p. 98). Em virtude da identidade entre o entendimento e a vontade em Deus, a Natureza é o que é para o entendimento: possibilidade realizada, condicionamento ontológico que não comporta o oculto, o descontínuo, o parcial, o rasgado. É preciso que ela seja redutível ao mecanismo, que dela se possa derivar a figura de um mundo de leis que exprimam a força interna de sua infinita produtividade. Tal Natureza é definida pela exterioridade radical de suas partes, sua unidade é aquela conferida por leis: natureza naturada.

O que chamamos Natureza é um naturado, um puro produto, feito de partes absolutamente exteriores, rigorosamente atuais e claramente ligadas, - 'concha vazia' dirá Hegel. Todo o interior passou para o lado de Deus, naturante puro (Merleau-Ponty 1968, p. 99).

Apreendê-la sobre fundo de um nada possível significa, pois, recusar-lhe toda forma própria de negatividade, confundi-la com o pensável. ${ }^{2}$

A concepção cartesiana da Natureza, segundo a "luz natural", permite entrever seus próprios limites e apontar para sua contra-efetuação. De fato, é porque o ser do pensamento se reconhece no mais alto ponto da dúvida, é porque a causa de si termina em uma hesitação que lhe é proporcional, que a perspectiva da "luz natural" deixa-se matizar por uma "inclinação natural" do corpo que permite acreditar no alcance existencial do que é fornecido passivamente pela sensibilidade. As pulsões do corpo vivente fazem vacilar o entendimento da coisa extensa, pois que "a experiência da existência não é redutível pelo entendimento puro" (1968, p. 100-101), ainda que não lhe seja incompatível. Em outros termos, coexistem em Descartes duas concepções da Natureza: como Acontecimento e como Objeto. Merleau-Ponty estima que essa dualidade dos sentidos - luz natural/inclinação natural - indicia algo da ordem de uma tensão ontológica, um "vai e vem das filosofias" que, longe de ser contradição, inadvertência ou incoerência, "seria justificada, fundada no ser". Afinal,

não haveria em toda nossa filosofia envio mútuo e círculo entre um pensamento que se poderia chamar 'positivista' (o ser é, Deus existe por definição, se algo devesse ser, isto não poderia ser senão esse mundo e essa natureza, o nada não tem propriedades), e um pensamento 'negativista' (a primeira verdade é aquela de uma dúvida, o que de início é certo é um meio entre o ser e o nada, o modelo do infinito é minha liberdade,

2 Cumpre lembrar como a Phénoménologie de la perception recrimina a análise reflexiva por encerrar no sujeito um naturante universal legitimador de suas experiências: corpo e eu empírico estão ligados ao mundo por leis da física e da psicofisiologia. Ora, é evidente que a sensação, desdobramento no "psíquico" das excitações sensoriais do empírico, somente pertencerá ao naturante universal à força de se ignorar essa "idéia bastarda" que é a de um espírito inscrito no tempo, vulnerável ao erro, à ilusão, às anomalias da percepção. Porque estes nunca serão dirimidos por qualquer saber, não se vê como manter intacta a constituição do eu empírico no Ego transcendental, espírito absoluto, sem história, e que nada separa do mundo verdadeiro (cf. Merleau-Ponty 1945, p. 55). 
este mundo é um puro fato) que inverte os signos e as perspectivas da primeira, sem poder eliminá-la nem coincidir com ela? Não há por todo lado a dupla certeza que o ser é, que as aparências não são mais que uma sua manifestação e restrição - e que essas aparências são o cânone de tudo o que podemos entender por 'ser', que nesse sentido é o ser em si que faz figura de fantasma inapreensível e de Unding?" (MerleauPonty 1968, p. 126-127).

Tensão, pois, entre uma ontologia do objeto - que fala de determinismos, transparecidos no entendimento - e uma ontologia do existente (ou do acontecimento) - que sublinha sua irredutível facticidade e privilegia a perspectiva dos sentidos. "Diplopia ontológica", nos termos de Merleau-Ponty, que solicita do filósofo que ele proceda, não à sua redução racional, mas à uma acepção de Ser onde abrigar suas contradições (cf. 1968, p. 128).

Não se trata de simplesmente acolher a dualidade. Mesmo porque, como mostra a leitura merleau-pontiana de Descartes, ocorre de em dado momento duas teses incompatíveis se apresentarem concomitantes. Tampouco conviria procurar suplantar a dualidade, pois que toda tentativa de redução dos dois termos a um terceiro reavivaria cedo ou tarde a dualidade. Donde o embaraço que caracteriza todo estudo da Natureza: não convém reter sua leitura dualista; contudo, não há síntese possível. Importa, antes, desvelar a intencionalidade em trânsito entre o universo das blosse Sachen e as "coisas pré-teoréticas", a "camada primordial das coisas intuitivas, percebidas" (1968, p. 112). ${ }^{3}$ Tratar-se-ia, portanto, de procurar por um meio ontológico, por uma textura comum que reúna o objeto e a consciência, e cuja dinâmica não tenha na dualidade do acontecimento reflexivo e do objeto determinado mais que um retrato abstrato. Essa é tarefa que exige desfazer o complexo ontológico característico da metafísica clássica, sua sistemática de apreensão da Natureza como o conjunto das ocorrências espaço-temporalmente determinadas e a produção natural como conformidade teleológica do acontecimento a um conceito (cf. 1968, p. 117). Afinal, considerações de totalidade o equacionamento entre a contingência do que existe e a legislação do entendimento - satisfazem apenas um empenho por antropomorfização na constatação, para além do que de fato constitui o ser natural, do feliz acordo entre nossas faculdades (cf. 1968, p. 104). A observação - que, aliás, faz pensar na crítica deleuziana, em Différence et Répétition, da analogia conjuntiva do senso comum - reforça em Merleau-Ponty a convicção de que "os conceitos do entendimento participam da contingência da experiência, [que eles] são sempre acrescidos de um 'coeficiente de facticidade' e ligados a uma estrutura tal como aquela do mundo" (1968, p. 105).

O corpo, órgão de um poder motor, é o lugar por excelência desse trânsito; contudo, sua pragmática é um tanto impeditiva: "Puisqu'il y a un corps-sujet, et puisque c'est devant lui que les choses existent, elles sont comme incorporées à la chair, mais en même temps notre corps nous projette des choses convaincantes, et nous en venons à croire aux 'pures choses', nous établissons l'attitude de pure connaissance, nous oublions l'épaisseur de la 'préconstitution' corporelle qui les porte" (Merleau-Ponty 1968, p. 113-114). 
Em razão dessa reciprocidade entre entendimento e experiência, todo quêstionamento mostra-se obrigatoriamente interno ao campo questionado. Implicações metodológicas à parte, evita-se de imediato a redução do mundo a uma pluralidade de objetos. Seria desconsiderar uma movência que investe indistintamente o sujeito questionante e os objetos questionados, englobando-os e modulandoos em uma mesma pertença. Dependente desse campo único de pertença, a questão não pode doravante se impor a partir de pontos de vista estritamente individualizados, ou externos ao campo de pesquisa, locados em um hipotético céu de intelectualidade pura, de modo a descobrir nos próprios registros seus critérios de veracidade (cf. 1945, p. 16). Nem a primazia do indivíduo a ser conhecido, nem aquela do sujeito de conhecimento e suas modalidades de expressão e pensamento, podem constituir de per si a motivação inicial de uma abordagem filosófica. Constrangido a advir ou do lado do sujeito ou do lado do objeto, o indivíduo a ser apreendido mostra-se apartado injustificadamente do mundo a que pertence. É, pois, um campo de pertença e sua movência que pedem pelo esforço da interrogação ontológica.

Ao contra-efetuar os pressupostos ontológicos da metafísica clássica, modo de recomeçar a filosofia sobre novas bases, Merleau-Ponty procura reabilitar a particular unidade do ser natural. Em Descartes, o naturante reflui do lado de Deus, de modo que a própria Natureza é apenas somatório de partes, sem unidade própria. Ora, há uma totalidade natural que não reenvia a um princípio positivo. O remanejamento relativista da física newtoniana, crítico de todo determinismo, conforta aqui a perspectiva ao evidenciar a impossibilidade do ponto de vista absoluto, circunscritor de cada ocorrência empírica em uma temporalidade única. Certas descrições filosóficas do mundo percebido permitem mesmo entrever um espaço do descontínuo, do provável. A percepção, evocada para além da ontologia substancialista laplaceana, é abertura não para seres definidos, "puras coisas", mas para "seres ambíguos [...] prováveis, que se reduzem a um feixe de probabilidades” (1995, p. 137). A física pósnewtoniana permite, assim, ver o que o ser seguramente não é: um composto contínuo de elementos; e mostra que mesmo a concepção laplaceana do Ser, à semelhança da ontologia do senso comum, não possui coerência absoluta (cf. 1995, p. 138). Os espaços não-euclidianos, por exemplo, evidenciam que o partes extra partes é apenas uma modalidade particular de espacialidade. Nem mesmo há sentido em interrogar acerca da natureza do espaço: enunciar a questão da natureza em si do espaço é admitir um Kosmosthéoros. Para seres viventes, lembra Merleau-Ponty, a questão não se impõe: "o espaço faz parte de sua situação; ora, um espaço de situação não é em si” (1995, p. 141). Ele é riemanniano tanto quanto euclidiano embora aquele permita melhor que este integrar os resultados da física moderna -, uma vez que, elemento construído pela ciência, o espaço nunca se destaca da contingência que deve a nosso contato carnal (cf. 1995, p. 142). ${ }^{4}$ Assim, a crítica que a

Perspectiva semelhante encontra-se em Gilbert Simondon (1995, p. 223): "rien ne nous prouve que nous puissions penser adéquatement le vivant à travers les rapports euclidiens. L'espace du vivant n'est peut-être pas un espace euclidien; le vivant peut être considéré dans l'espace euclidien, où il se définit alors comme un corps parmi des corps; la structure même du vivant peut être décrite en 
física relativista motiva das métricas euclidianas incita a romper com uma sensibilidade desengajada da situação do observador, e fornece o seu sentido ontológico ao polimorfismo do espaço e do tempo percebidos (cf. 1968, p. 120).

Em lugar da objetividade dogmática de um Laplace, o que se entrevê no "comjunto de verdades negativas" apresentadas pela ciência e recolhidas pela filosofia (cf. 1995, p. 146) é a garantia de reconhecimento dada pela pertença da multiplicidade dos observadores carnais, sujeitos em situação, a um mesmo núcleo de ser ainda amorfo. Ocorre, porém, de o físico relativista multiplicar as visadas egocêntricas sucessivas em lugar de operar a coexistência filosófica da temporalidade dos diferentes observadores. Com o que manter o mundo pensado na sucessão dos pontos de vista e não na sua simultaneidade. Razão porque ao filósofo compete, partindo da relatividade inerente a cada particular ponto de vista, esclarecer o registro da coexistência, da simultaneidade dos pontos de vista; em outros termos, "o sentido profundo de nossa situação singular e de nossa pertença a um mesmo mundo" (1995, p. 149).

Ora, Merleau-Ponty lembra como a física moderna descortina um Ser maciço, onde tempo, espaço, matéria não aparecem como realidades justapostas, mas como uma única realidade indivisa (cf. 1995, p. 145-146). É Whitehead quem respalda essa concepção da Natureza como Acontecimento maciço. Nela, contrariamente à concepção clássica de um todo desenrolado ao longo da infinidade de pontos temporais e espaciais, as diferentes existências espaço-temporais compactuam de uma mesma "confusão ontológica" (1995, p. 153). Ao longo da tradição científica, espaço e tempo não têm sido mais que modos abstratos de determinação das relações entre as individualidades no interior de um acontecimento global. De fato, uma perspectiva substancialista limita-se a deduzir as condições de existência da substância dos "objetos macroscópicos da experiência”. Interessa-lhe fazer falar, no plano molar, o passado como razão suficiente do presente, e a serialização causal dos tempos, que exclui o fluxo inerente à constituição molecular do mundo e dos indivíduos particulares (cf. Alliez 1995, p. 48). Em contrapartida, Merleau-Ponty endossa a metafísica do fluxo de Whitehead, atenta ao modo como os diversos tempos e as diversas temporalidades incompossíveis formam, mais que uma "sucessão perfeitamente nítida de instantes", "sistemas de conexões materiais sutis", em consonância com os "fatos brutos" e com as bordas "esfarrapadas" da Natureza (Merleau-Ponty 1995, p. 153 e 59, respectivamente). Dessa maneira, compor o mundo a partir de existências espaço-temporais pontuais, como "poeira de eventos", é fazer abstração do que entre eles está de fato em fluxo (em "passagem") ou, no máximo, conceber-lhes relações seriais, fronteiras exteriores (cf. 1995: 154). ${ }^{5}$

termes euclidiens. Mais rien ne nous prouve que cette description soit adéquate. S'il existait un ensemble de configurations topologiques nécessaires à la vie, intraduisibles en termes euclidiens, on devrait considérer toute tentative pour faire un vivant avec de la matière élaborée par la chimie organique comme insuffisante: l'essence du vivant est peut être un certain arrangement topologique que l'on ne peut connaître à partir de la physique et de la chimie, utilisant en général l'espace euclidien".

5 A crítica que Merleau-Ponty move contra a temporalidade serial favorece o que ele chama a "éternidade do visível". Em termos de carnalidade englobante, não há porque se perguntar como um passado pode persistir em um presente que o suprime, pois que, apreendido em sua verticalidade, 
Em momentos diversos, Merleau-Ponty insiste no fato de o pensamento supor um espaço em eco, ou melhor, uma pluralidade de espaços encerrados uns nos outros, labirínticos, folhados, sobrecondensados e sobreocupados. Em outros termos, o pensamento é horizonte de convocação simultânea dos vários eventos espaço-temporais, mais que processo de redução à pontualidade deste ou daquele em-si. ${ }^{6}$ Espaço por excelência de contágio - não por acaso Whitehead é convocado para se contrapor ao pensamento que "repousa sobre a idéia de um ponto 'flash'” (1995, p. 154) -, o pensamento é a exata contra-efetuação do espaço clássico, "demasiado limpo", insensível às porosidades e às franjas irregulares de um mundo pré-individual em formação. Insensibilidade que configura a "descida" da idealidade no registro da consciência singular e a "subida" desta ao ser ideal por sobre toda individualidade instalada em um ponto do tempo e do espaço. A espacialidade clássica é ranço de uma ontologia do ob-jecto, unidade formal correlativa de uma contenância regrada no espírito. Uma ontologia do "elemento" vem substituí-la, o que permite falar de relações de "imbricação", de "implicação", de "passagem" dos acontecimentos uns nos outros.

Essa passagem da Natureza, que assegura a interioridade dos acontecimentos uns nos outros, nossa inerência ao Todo, liga os observadores uns aos outros. Ela é o que réune. A passagem da Natureza é aqui representada fazendo progressos, anexando para si o corpo dos sujeitos. Em outros termos, a passagem da Natureza, que corresponde à unidade do corpo sentiente e, já que o corpo é ele próprio acontecimento, faz a unidade do corpo, bem como a unidade dos diferentes observadores; ela é também uma Natureza para vários" (Merleau-Ponty 1995, p. 159).

o passado não é negado pelo presente, mas lhe é contemporâneo. A sucessividade, isto é, a relação de negação ou de exclusão entre os instantes não se opõe à eternidade do mundo que estes instantes comunicam. Há, sim, uma presença do passado no presente, pois que não são momentos ordenados sucessivamente, mas dimensões do mesmo mundo e, como tais, contemporâneos. Conseqüentemente, a memória é pensável sem substrato psíquico, ela que repousa sobre uma "memória do mundo": "le paysage visible sous mes yeux est, non pas extérieur à, lié synthétiquement aux autres moments du temps et du passé, mais les a vraiment derrière lui, en simultaneité, au-dedans de lui et non lui et eux côte-à-côte dans le temps" (Merleau-Ponty 1964, p. 321). A contemporaneidade dos tempos é conseqüência, não causa, de um Espaço originário que os envolve.

6 Em nota de trabalho, lê-se: "[...] le monde, l'Être, sont polymorphisme, mystère et nullement une couche d'étants plats ou d'en soi". E, um pouco mais abaixo, a precisão: "Ceci est à appliquer non seulement à la perception, mais aussi bien à l'Univers des vérités prédicatives et des significations. Ici aussi il faut concevoir la signification (sauvage) comme absolumment distincte de l'En Soi et de la 'conscience pure' - la vérité (prédicative-culturelle) comme cet Individu (antérieur au singulier et au pluriel) sur lequel se creusent les actes de significations et dont elles sont des copeaux" (Merleau-Ponty 1964, p. 306). A tópica repensada para um ser de promiscuidade, de integração "où les 'modes de conscience' s'inscrivent comme des structurations de l'Être [...], et où les structurations de l'Être sont des modes de conscience" - é, sobretudo, contra-efetuação do que MerleauPonty chama as "realidades psíquicas" (as "Erlebnisse", as "sensações", os "juízos"), idealizações da Psique e da Natureza porque "lacunares", "insulares", "sem Weltlichkeit própria" (ou seja, sem energia de expansão, de integração); enfim, "découpage abstrait dans l'étoffe ontologique, dans le 'corps de l'esprit'“ (1964, p. 307). O estofo do Ser, ressalta Merleau-Ponty, é indistintamente cultural e natural, pois que mesmo o concebido repousa sobre o polimorfismo do Ser selvagem. Priorizar, portanto, o estudo da Natureza de modo algum incorre em empirismo: há uma verdade do naturalismo, sem ser propriamente naturalismo (cf. 1968, p. 112). 
O acontecimento opõe-se naturalmente ao objeto, na medida em que a idéia de um "éter dos acontecimentos" como substância última da matéria é, na verdade, subtração a toda noção de substância. Se a matéria é tomada como entidade substancial, da qual os fenômenos são tão somente os atributos, sua experiência, por simples procedimento de pensamento, seria o ato de condução do atributo à substância. Ora, o motivo da "passagem" (do fluxo) subverte radicalmente tal perspectiva. Não é mais uma substancialidade de localização única que torna possível a concepção do objeto e do acontecimento. Doravante, o objeto será "o modo abreviado de marcar que houve um conjunto de relações" (1995, p. 158) que a experiência percorre como uma "constelação" do mundo, investida de movimentos de contração e dispersão.

A consideração do compromisso mútuo entre os acontecimentos e da inerência da consciência a modos de passagem, a revelação da Natureza "como aquilo no qual estamos, aquilo ao qual estamos misturados" (1995, p. 164), além de desqualificarem a figura de um observador imparcial apartado das relações naturais, opõem-se à idéia de Natureza como "correlativa de uma exterioridade legal, de um pensamento" (1995, p. 165). Na verdade, a Natureza oferece-se a uma "pululação ilimitada das categorias", exatamente como na percepção a revelação sensível é o que se mantém paradoxalmente distante por sua própria viscosidade. Merleau-Ponty mostra que a contração do Sensível nas tramas da objetividade ou da síntese subjetiva é amplificação desmesurada da confiança intelectual no idêntico e no individuado. Fato é que a filosofia e a ciência têm recusado historicamente o ambíguo, o indeterminado, o latente e o aberto em favor do transparente, do determinado, do completo e do fechado. Assim, ambas evitam numerosas interrogações concernentes a uma renovada metafísica da experiência. Por isso mesmo Merleau-Ponty lembra que para o mundo euclidiano o mistério é repressão da transcendência; e que a simultaneidade é "mistério que os psicólogos manobram como uma criança o faz com os explosi-

\footnotetext{
"Constelações gerais" são configurações, "estruturas quase sensíveis" de raios de mundo e raios de tempo - lugares por excelência da potencialidade merleau-pontiana -, caminhos descontínuos e lacunares da consciência em substituição aos "eu penso que" seriados (cf. Merleau-Ponty 1964, p. 293). Através delas, as idéias e experiências são investidas do poder de contaminação, infiltração, ressonância, ação à distância de uma unidade que se poderia chamar unidade de participação ou unidade transdutiva. O motivo da "constelação" é suficientemente fértil em Merleau-Ponty para motivar Jacques Garelli a cunhar a expressão "constelação pensante" em referência ao lugar da obra (pictórica, em particular): "système d'échanges interrogatifs, qui se croisent en son lieu et qui en font un théâtre d'animation, un système métastable en phase d'individuation [...], champ spatialisant [d'où] se prononce l'opération d'individuation 'donnant lieu' à l'ordonnance des formes se structurant selon le jeu des lignes, des masses et des couleurs [...], 'Constellation pensante' dont le peintre à l'oeuvre en son projet portant sur la toile, ouvre le champ, dans le même mouvement où il ordonne les formes, les masses, les couleurs, qui ne sont autres que les composantes spatialisantes de son questionnement" (1991, p. 345-346). Contrafeito à inércia espacial da res extensa, o lugar de criação em Merleau-Ponty é abertura do mundo sobre si mesmo, processo de "mundialização em obra". Explorar a análise da noção de Natureza visa aqui, fundamentalmente, percorrer em seus termos mais gerais o roteiro de pesquisa que confortou Merleau-Ponty na concepção do pensamento sob fundo de transindividualidade ativa. Em outras palavras, o que o motiva ali é o processo do pensamento em formação: a "selvageria" por assim dizer da experiência de criação realiza a irradiação inesgotável das variações do pensamento, no mesmo movimento em que ela se realiza em obra, isto é, ao mesmo tempo em que ela se ordena (se individua) em mundo.
} 
vos" (1964a, p. 84). Ora, uma Natureza revista na chave da pré-individualidade possui "coesão por incompossibilidade", "simultaneidade por recorte dos campos visíveis finitos, coexistência carnal, coduração" (1996, p. 199-200).

Se a experiência do sensível não é originariamente experiência de pensamento, como então explicar que diferenças internas nasçam do mesmo estofo-mundo e se enderecem ao mesmo mundo? O que é este "mesmo" habitado pelo "outro" em razão de sua própria ontogênese? Face aos incompossíveis, não basta desfazer os pares, pois que o par é mais real que os termos que, aliás, não pré-existem à relação como sua razão suficiente. Quanto ao nó, ao entrelaçamento dos fios intencionais, não basta objetivar "distendê-los" para fazê-los aparecer, nem dizer que cada lado vai em uma direção, pois que "lado" é modo de falar e pensar próprio ao espaço euclidiano, onde o relevo, a diferenciação e a simultaneidade são rebatidos em uma multiplicidade plana e projetiva. Enfim, por força desses interditos, o que perde legitimidade é a idéia de Natureza fixa, estável, fundamental, primeira e definitiva, ilusória permanência transportada pelo entendimento ao percebido, quando na verdade ela é dimensão de modulação do mundo. Tanto mais que a permanência substancial da coisa idêntica a si, regida pelo princípio de identidade, impossibilita que um ser seja locado ali onde de fato se manifesta, qual seja, na simultaneidade de si e de seu outro.

O sensível é irredutível ao princípio de identidade: ao conter sua própria negação, ao ser seu próprio excesso ou recuo, é "pré-individualidade" (Merleau-Ponty 1964, p. 315). Infensa a todo princípio substancial de individuação, a ontologia desse sensível e a noção de experiência ali suposta recebem tônus do abandono do registro de um ente individuado, resolvido na relação entre res cogitans e res extensa. Em seu lugar, notabiliza-se a indistinção entre individuação e pertença ao mundo, o devir si e a abertura para o outro, identidade e diferença. O que não deixa de reforçar a convicção de que o sensível merleau-pontiano ganha relevo ao ser aproximado do motivo da metastabilidade: movimentos de integração entre estruturas por vezes dicotômicas relevariam sua carga potencial, seu nível de ressonância interna que as reconduz à pré-individualidade do mundo. O vivente é, nesse sentido, evocação de uma dimensão participativa, definidora de toda relação sensível. Como observa Gilbert Simondon (1995, p. 27),

a relação não surge entre dois termos que já seriam indivíduos; ela é um aspecto da ressonância interna de um sistema de individuação; ela faz parte de um estado de sistema. Esse vivente que é a um só tempo mais ou menos que a unidade comporta uma problemática interior e pode entrar como elemento em uma problemática mais vasta que seu próprio ser. A participação, para o indivíduo, é fato de ser elemento em uma individuação mais vasta por intermédio da carga de realidade pré-individual que o indivíduo contém, isto é, graças aos potenciais que ele encerra (grifos do Autor).

Porque situada em um plano mais fundamental que os mecanicismos e finalismos, que trabalham no registro de uma causalidade localizada, toda individualidade é portadora de potencialidade que a qualifica como criação continuada, devir de individuação. 
Não é, pois, casual se ao longo da história do pensamento e da expressão individualidades em devir - o pedaço de cera de Descartes, o pedaço de giz de Heidegger, a madeleine de Proust, a raiz da árvore de Sartre, o cinabre de Kant, o seixo de Valéry - têm obsedido a concepção de uma identidade substancial como termo primeiro dos atos questionantes. Transbordamentos e metamorfoses abrem esses "objetos" para horizontes de movência do mundo que impedem sua redução objetiva à permanência do ente individuado. A noção do sensível como "préindividualidade" torna equivocada toda identidade a si e em si, apartada do mundo.

Tal perspectiva contempla igualmente a individuação vital. Modelar, a propósito, é o motivo da vida vegetal como "um nó interelementar [que] se desenvolve como ressonância interna daquele sistema pré-individual feito de duas camadas de realidade primitivamente sem comunicação" (Simondon 1995, p. 32): a ordem cósmica do atmosférico e aquela inframolecular da química da terra. A síntese química do solo absorvida pelas raízes e a fotossíntese da luz produzida pela folhagem deixam ver que um vegetal não é delimitado por suas fronteiras visíveis. Por força de um "trabalho intraelementar", sua individualidade "transita" por assim dizer do solo calcário e argiloso às radiações cósmicas do firmamento. Em suma, por sua ressonância interna a um sistema pré-individual, todo vivente constitui uma dimensão ou fase do mundo. Irredutível a qualquer individualidade substancial, delimitada e idêntica a si, seu questionamento não pode ser desimplicado da dimensão transindividual do mundo em individuação de que faz parte. Toda individualidade, insiste Simondon, é relacional, transicional; cada diferenciação sua exprime, pois, uma potencialidade do todo. Com o que Simondon retoma Whitehead, à semelhança de Merleau-Ponty, em sua acepção do organismo como "processo de individuação" ontologicamente mais profundo que o indivíduo, ${ }^{8}$ como expressão momentânea da "criatividade do mundo": "mônada fluida", "passagem", "acontecimento"..

Em chave diversa, Deleuze chega a conclusão semelhante no apelo que faz à concepção de morfogênese de Uexküll: uma "Natureza melódica, polifônica, contrapontista” evidencia relações de modulações entre modos diversos de vida. Habitats de uma mesma espécie podem encontrar seu contraponto em uma outra

8 Lê-se: "Il n'y a pas d'individu élémentaire, d'individu premier et antérieur à toute genèse" (Simondon 1995, p. 127); "Le devenir n'est pas devenir de l'être individué, mais devenir d'individuation de l'être" (1995, p. 277).

9 Correlativamente, em comentário acerca da sensação whiteheadiana como ressonância interna, Eric Alliez (1995, p. 58-59) esclarece: "In-dividuação, in-formação, enjoyment e self-enjoyment através do que os seres afetam-se a si próprios criando-se, mistério da paixão e da criação continuada, a sensação é injecto [...] 'não são as idéias que contemplamos pelo conceito, mas os elementos da matéria, por sensação. A planta contempla contraindo os elementos dos quais ela procede, a luz, o carbono e os sais, e se preenche a si mesma com cores e odores que qualificam sempre sua variedade, sua composição: é sensação em si' [Whitehead]. Contemplação quer dizer fotossíntese sensível daquilo que se infinita entre o cósmico e o elementar. O que equivale a pôr que a sensação implica, por uma 'identidade sem sujeito funcionário', o Pensamento como processualidade sensível, maneira de ser, acontecimento do universo. Pensar a sensação como a paixão universal do pensamento". 
espécie que lhes estende as funções originais, sem com isso evocar uma finalidade da Natureza. O que transparece aqui é a permuta incessante de "motivos" entre melodias diversas que conformam "compostos de sensações", "blocos" e "devires" em uma espécie de "plano de composição sinfônica infinito" feito indistintamente de alternâncias e confrontos. ${ }^{10}$ A perspectiva tem o mérito de se desdobrar em um modelo de pensamento onde "cada elemento criado em um plano apela para outros elementos heterogêneos, que ficam por criar nos outros planos: o pensamento como heterogênese" (Deleuze 1991, p. 188).

Tal modelo é mutacional mais que evolucionista, em parte semelhante àquele que Merleau-Ponty intui em sua crítica ao darwinismo. "Que estatuto dar à totalidade?": esta questão irradia das ciências naturais e vem se colocar não somente no centro das análises de Merleau-Ponty da idéia de Natureza, mas forçosamente de toda a filosofia. Razão, pois, para convocar teorias atualizadas do comportamento em embriogênese, sensíveis a uma totalidade não causalisticamente redutível a suas partes. Em seu conjunto, o organismo apresenta uma totalidade por assim dizer "emergente". O vivente é como um turbilhão, o organismo é um "macro-fenômeno" ou um "fenômeno-invólucro" que investe o local/instantâneo situado entre suas componentes, isto é, em toda parte e em parte alguma. "A estabilidade do organismo é uma estabilidade ininterruptamente reconquistada e comprometida" (Merleau-Ponty 1995, p. 200), de modo que falar de funcionamento mecânico ou de irrupção na matéria de um princípio é propor figurações abstratas dessa dinâmica. Há, na verdade, "aderências" entre as partes espaciais e temporais de uma vida, "modulação de uma mesma vida" (1995, p. 203). A figura de um sujeito pré-formado esbarra mesmo na tese da epigênese da embriologia moderna. De maneira que, na seqüência de sua análise, Merleau-Ponty é levado a concluir:

a física moderna não mais se restringe a representar os processos como somas de pontos. Não se quer pois dizer que o futuro está pensado no presente, mas somente que a pluralidade dos fenômenos se encaixa e constitue um conjunto dotado de sentido. Hegel já comparava a vida a um turbilhão: o turbilhão não é senão água, mas sua forma não se explica pela água. O organismo não seria uma totalidade transcendente, muito menos uma totalidade por somatório (Merleau-Ponty 1995, p. 203-204).

A perspectiva tem o mérito de reabilitar o negativo, isto é, de recusar a pensá-lo segundo uma oposição maciça ao ser pleno. Mais que uma mecânica dos acontecimentos (sua serialização), há uma autodiferenciação como modo de existência, ou seja, um campo ou um mundo em permanente devir. Emprestando a

Lê-se: "C'est que le territoire ne se contente pas d'isoler et de joindre, il ouvre sur des forces cosmiques qui montent du dedans ou qui viennent du dehors, et rend sensibles leur effet sur l'habitant. C'est un plan de composition du chêne qui porte ou comporte la force de développement du gland et la force de formation des gouttes, ou de la tique, qui porte la force de la lumière capable d'attirer la bête à la pointe d'une branche, à une hauteur suffisante, et la force de pesanteur avec laquelle elle se laisse tomber sur le mammifère qui passe - et entre les deux rien, un vide effarant qui peut durer des années si le mammifère ne passe pas. Et tantôt les forces se fondent les unes dans les autres en transition subtiles, se décomposent à peine entrevues, tantôt elles alternent ou s'affrontent" (Deleuze 1991, p. 176). 
perspectiva de Raymond Ruyer, Merleau-Ponty confirma o quadro já traçado pela ontogênese do sensível:

a realidade dos organismos supõe um Ser não-parmenidino, uma forma que escapa ao dilema do ser e do não-ser. Pode-se então falar de uma presença do tema dessas realizações, ou dizer que os acontecimentos estão agrupados em torno de uma certa ausência [...] a totalidade está por toda parte e em parte alguma [...] Os fenômenos da vida giram em torno de certas charneiras. Os temas são ainda dimensões, a instauração de um certo campo de gravidade (Merleau-Ponty 1995, p. 239-240).

Cada acontecimento orgânico é polarizado por uma totalidade que é tão somente seus modos de atualização. A vida caracteriza-se por um "não-ser operante", por uma falta nunca qualificada, "falta disso ou daquilo" (1995, p. 207), razão porque ela transcende a alternativa do mecanicismo e do finalismo: ela não é mecanismo, pois que o organismo é polarizado pelo futuro e, portanto, mais que ele próprio; nem por isso ela releva da finalidade, pois o que dinamiza o vivente não é um ser transcendente e positivo, o devir do vivente sendo tributário de cada uma das etapas efetivas sem contudo ser explicado por seu somatório.

Há problema na vida, e o problema não é somente evocado quando as soluções já estão ali. O princípio negativo é menos identidade consigo que não-diferença consigo. Essa ausência somente se torna fator por negação de sua própria negação. É menos uma unidade do múltiplo no vivente que uma adesão entre os elementos do múltiplo (Merleau-Ponty 1995, p. 208). ${ }^{11}$

Não há como deixar de remeter uma vez mais à perspectiva simondoniana do vivente como "ser problemático", a um tempo superior e inferior à unidade. Dizêlo problemático é considerá-lo segundo uma axiomática aberta, é tomar o devir como sua dimensão originária. O vivente opera por mediações, é agente e teatro de individuações permanentes, ou melhor, de "uma série de individuações que avançam de metastabilidade em metastabilidade" (Simondon 1995, p. 27). Ele é menos equilíbrio que estado de tensões conservado no equilíbrio de metastabilidade (cf. 1995, p. 224). Assim, o que a substancialização da realidade individual considera como relação é, na verdade, uma dimensão de individuação através da qual o indivíduo advém: a relação com o mundo e com o todo é uma dimensão de individuação da qual ele participa a partir da realidade pré-individual, que por sua vez se individua ininterruptamente. Enfim, os problemas vitais não estão fechados em si mesmos; sua axiomática aberta somente pode ser cancelada por uma série indefinida de individuações sucessivas, de modo que "a ontogênese é uma problemática perpetuada, saltando de resolução em resolução” (1995, p. 224). ${ }^{12}$

11 Lê-se ainda: "[...] La vie est incompréhensible pour la philosophie de la chose (mécanisme et vitalisme) comme pour la philosophie de l'idée, et ne s'éclaire que pour une philosophie du 'quelque chose' ou, comme on dit aujourd'hui, de la structure" (Merleau-Ponty 1968, p. 173).

12 A perspectiva ganha em nitidez quando da análise da invenção da profundidade pelo organismo, de seu modo de dar sentido a duas imagens retinianas disparatadas: "Il y a disparation lorsque deux ensembles jumeaux non totalement superposables, tels que l'image rétinienne gauche et l'image rétinienne droite, sont saisies ensemble comme un système, pouvant permettre la formation 
Está claro que a determinação do ser natural como totalidade em devir, como envolvimento em uma dimensão de negatividade, resulta no abandono do recorte entre essência e existência. De fato, se a natureza física é concebida como passagem global ou acontecimento maciço, segue-se que toda localização espaçotemporal, "ponto-flash" na terminologia de Whitehead, é já uma abstração, e que, em sua textura real (natural) o acontecimento transcende o espaço e o tempo, é "transespacial e transtemporal" (1995, p. 230). O que o tema da melodia animal, que Merleau-Ponty retoma de J. von Uexküll, permite ilustrar: "em uma melodia, uma influência recíproca entre a primeira e a última nota tem lugar, e devemos dizer que a primeira nota somente é possível pela última, e reciprocamente. É assim que as coisas se passam na construção de um vivente" (Merleau-Ponty 1995, p. 228). Na temporalidade inerente a um fluxo melódico, é impossível distinguir meio e fim, essência e existência. Se o todo orgânico não é a soma de suas partes locais, se tampouco remete a um princípio transcendente, cumpre reconhecer-lhe um modo de existência ubiqüitário, como o que atravessa e liga as partes locais sem objetivo previamente esclarecido. Nessa travessia, exterior e interior, situação e movimento "não estão em uma relação simples de causalidade e não podem ser traduzidos em termos de 'causalidade lançada' do antes ao depois" (1995, p. 229). Um comportamento não se deixa compreender de instante a instante, cada ação não guarda uma utilidade separada, mas faz sentido somente à luz da situação de reciprocidade do conjunto. ${ }^{13}$ Há nisso, e Merleau-Ponty repete aqui Uexküll, "envolvimento dos Umwelten uns nos outros": "nós vivemos um no Umwelt [meio ambiente] do outro" (1995, p. 232), ${ }^{14}$ de modo que um meio de acontecimento abre um campo espacial e temporal.

d'un ensemble unique de degré supérieur qui intègre tous les éléments grâce à une dimension nouvelle (par exemple, dans le cas de la vision, l'étagement des plans en profondeur)" (Simondon 1995, p. 223). Perceber não seria, pois, a apreensão de uma forma que se impõe, como deixa entender a Gestalttheorie, "mais la solution d'un conflit, la découverte d'une incompatibilité, l'invention d'une forme" (Simondon 1989, p. 76). A "boa forma" é produzida a partir da "tension entre deux réels disparates" (Simondon 1995, p. 15); ela não anula essas tensões, torna-as compatíveis; a resolução faz-se pela "signification qui surgit lorsqu'une opération d'individuation découvre la dimension selon laquelle deux réels disparates peuvent devenir système". Em outras palavras, a "boa forma" resolve a incompatibilidade sem anulá-la em sua diferença.

13 A propósito do movimento melódico como modelo para o movimento vital, retenha-se o que descreve Jan Patocka (1995, p. 108): “[dans une composition musicale] chaque élément n'est qu'une partie de quelque chose qui l'excède, qui n'est pas là d'emblée sous une figure achevée, quelque chose plutôt qui, préparé dans toutes les singularités, demeure toujours, en un certain sens, à-venir, aussi longtemps que la composition se fait entendre [...] De même qu'une composition polyphonique est un mouvement unitaire, composé derechef de mouvements dont chacun possède son sens autonome, modifié de manière spécifique par le sens des autres mouvements - de même le mouvement de notre existence se déroule lui aussi dans plusieurs zones de mouvements relativement autonomes dont aucune ne peut être prise en vue exclusivement pour soi, et qui se modifient et exercent une influence les unes sur les autres".

14 Um pouco antes, Merleau-Ponty explicara (1995, p. 220): "L'Umwelt marque la différence entre le monde tel qu'il existe en soi et le monde en tant que monde de tel ou tel être vivant. C'est une réalité intermédiaire entre le monde tel qu'il existe pour un observateur absolu et un domaine purement subjectif. C'est l'aspect du monde en soi auquel l'animal s'adresse, qui existe pour le comportement d'un animal, mais non forcément pour sa conscience, c'est l'entourage de 
As notas de trabalho de Le visible et l'invisible apontam para o que desse envolvimento transparece em uma "história ontológica": a filosofia como "círculos que se envolvem", a explicitação do Umwelt da ontologia ocidental como "conexão dos conceitos: Ser, Natureza, Homem", ainda que não exaustiva, pois o que se liga não são essências, mas fios de uma "história vertical desordenada". Assim,

o que proponho não é uma 'visão' da história da filosofia. Ou é história, mas estrutural: isto é, não a ocorrência de tal filosofia como criação e solução de 'problemas', mas essa filosofia situada no conjunto hierático do Ser e da eternidade existencial, isto é, num conjunto interrogativo [...] (Merleau-Ponty 1964, p. 241; grifos do Autor);

$\mathrm{E}$, mais à frente:

redescrever toda a vida inter-humana e mesmo espiritual nestes termos, a Weltlichkeit do espírito, sua não insularidade, seus laços com os outros espíritos e com a verdade, também devem ser compreendidos como diferenciações de uma arquitetônica espáciotemporal (Merleau-Ponty 1964, p.: 285).

Tal perspectiva visa desconstruir uma arquitetônica positivista do mundo apóiada na experiência do corpo fisiológico, assim como toda correspondência causalista entre corpo e alma (e seu correlato, forma-matéria). Nesse esforço, o modelo vem, uma vez mais, da embriologia:

Quando o organismo do embrião começa a perceber, não há criação pelo corpo em si de um Para-si e não há descida ao corpo de uma alma preestabelecida, acontece que o turbilhão da embriogênese repentinamente se centra sobre o oco interior que ela preparava - Certo afastamento fundamental, certa dissonância constitutiva emerge (Merleau-Ponty 1964, p. 287).

Ao falar de "turbilhão", "dissonância”, essa perspectiva procura esclarecer como uma processualidade se constitui: aos moldes de uma existência geral. Existir na natureza ou como natureza não é estar situado em um ponto do espaço e do tempo. O que não significa, bem entendido, que a natureza seja estranha ao espaço e ao tempo, mas que estes não designam uma ordem ou um elemento indiferente aos acontecimentos que ali sobrevêm. Mesmo porque "um Umwelt não é absolutamente a posição de um objetivo", pois que a finalidade é invariavelmente imperfeita, "ora aquém ora além do útil" (1995, p. 230). Razão porque toda individuação não se dá como inscrição de uma qualidade ou de uma determinação no registro espacial e temporal, mas antes como espacialização e temporalização inerentes à qualidade. 0 acontecimento natural não existe no espaço-tempo, mas como espaço-tempo; não se desdobra no interior do espaço-tempo, desdobra o espaço-tempo. Nesse sentido, dizer com Merleau-Ponty que a existência natural é uma existência geral equivale a reconhecê-la como o que alinhava as localizações espaciais e temporais, os "pontos-flash", sem se distinguir da pluralidade dos acontecimentos através dos quais ela se atualiza.

comportement [...]". Em Deleuze, como se viu, o Umwelt é conformado, ora pela transição sutil entre as forças, ora por seu enfrentamento violento; ora favorece a sedentariedade, ora a longa peregrinação, evidenciando uma rítmica nada linear da Natureza, imagem que aliás obsede a consciência moderna. 
O que manifestamente desaparece de cena é a matéria como existência molecular no tempo e espaço. Igualmente todos aqueles processos de "enxugamento" conceitual que remetem os sensíveis à unicidade de um mundo inteligível intemporal. Mesmo a essência é fecunda, ressalta Merleau-Ponty, "porque clama por pluralidade em lugar de suplantá-la". ${ }^{15}$ A generalidade da essência equivale à sua transespacialidade e transtemporalidade, isto é, à pluralidade dos acontecimentos que ela engloba. Poder-se-ia afirmar que o espaço-tempo, no sentido descrito por MerleauPonty, é a essência da essência. Em várias oportunidades, ele assume a realidade como uma tarefa a cumprir. O que significa dizer que ela só existe como seu próprio processo de atualização, que é sempre processo de diferenciação. A realidade não é um salto incompreensível da essência na existência - "o comportamento 'não desce' no organismo 'como uma visitação do alto"' (1995, p. 200) -, mas a atualização de uma virtualidade. O virtual é apenas o conjunto de suas atualizações, que são infinitas; porém delas se distingue precisamente por ser potência dessa infinidade e porque nenhuma atualidade esgota sua fecundidade.$^{16}$ Talvez se devesse admitir que a noção de real não está forçosamente ligada àquela de ser molecular. "Por que não haveria ser molar? O modelo do Ser estaria alhures que não no corpúsculo, por exemplo, em um ser da ordem do Logos, não mais da 'pura coisa'" (1995, p. 209).

Se para Merleau-Ponty a ontologia da Natureza é o meio mais indicado para afirmar a necessidade de uma mutação ontológica - do Ser euclidiano e causal da ciência ao Pré-Ser em fluxo da experiência vivida -, ela o é na convicção de que todo reducionismo de nossa visada global, no empenho por surpreender o ser individuado a tal ponto e a tal instante, invariavelmente o reporta a seus condicionantes fisico-químicos (cf. 1995, p. 267). De modo que a investigação da Natureza não é particularizante: se ela é tarefa para o que chamaríamos uma "intra-ontologia", onde a intencionalidade é envolvimento com o todo, ela não mais investiga a ordenação de nossas razões, mas o caráter folhado do Ser, o nexus, o vinculum dos seres. O Logos, aqui, é o de uma filosofia da perspectiva e de uma filosofia do Ser vertical, onde a humanidade é antes filigrana que substância. Pensar nesse registro a essência do homem como a de um ser por natureza inacabado, direcionado à "perpétua esquiva" supõe, de imediato, rejeitar todo finalismo:

"Não sou finalista porque existe deiscência e não produção positiva, - através da finalidade do corpo, - de um homem cuja organização teleológica seria prolongada pela nossa percepção e pelo nosso pensamento. O homem não é o fim do corpo, nem o

15 Manuscrito inédito, apud Barbaras, R. "Merleau-Ponty et la nature”. Disponível em

http://www.ac-toulouse.fr/philosophie/forma/barbaras.htm.

6 Aqui, a ontogênese oferece ao filósofo seu modelo de possível menos falseador: "[...] le sac à possibles d'où un choix tirerait le possible convenable est une illusion : le 'choix' est fait par des déterminations déjà acquises qui jouent le rôle directeur, le sac à possible est illusoire, il y a autorégulation du processus qui se relance et fournit les diverses actualités observables" (MerleauPonty 1995, p. 297). Assim, na aproximação com a intencionalidade criadora, vale observar como na execução de um quadro a quantidade de fios que "se nouent, qui proviennent de partout, et qui constituent des formes indépendantes" (1995, p. 205), ainda que pareçam realizar uma unidade, não autorizam o pintor a procurar uma lógica de resolução do halo de possíveis imprevisíveis que aparecem ao primeiro signo, ao primeiro fio: há uma ação em retorno por parte do mundo que se cria, relançando o comportamento criador. 
corpo organizado o fim dos componentes: mas antes o subordinado oscila, de cada vez, no vazio de uma nova dimensão aberta, o inferior e o superior gravitam um em torno do outro, como o alto e o baixo (variantes da relação lado-outro lado) - No fundo, eu arrasto a distinção alto-baixo para o turbilhão onde ela se reúne à distinção ladooutro lado, onde as duas distinções se integram numa dimensionalidade universal que é o ser (Heidegger)" (Merleau-Ponty 1964, p. 319; grifos do Autor).

Já que esse regime de basculamento no vazio das dimensões não é tradução entre idéias, conceitos ou significações, ele impõe a anulação da hierarquia entre diferentes "ordens": o sensível, o intelectivo, o ideal, o real, etc. Não há, de fato, anulação de "ordens inferiores" por "ordens superiores", pois que elas não se acumulam umas sobre as outras em camadas lineares. Trata-se, antes, de relação entre circularidades - meu corpo-o sensível, eu-outro - que "se prolongam" sem, contudo, se fecharem em uma totalidade plena denominada "o humano". O homem, Merleau-Ponty conclui, deve ser tomado no Ineinander com a animalidade e a Natureza, avançando assim para além do seu sentido clássico como animalidade mecânica acrescida de razão.

Trata-se de apreender a humanidade inicialmente como uma outra maneira de ser corpo - de ver emergir a humanidade também como Ser em filigrana, não como uma outra substância, como interser e não como impostação de um para si a um corpo em si (Merleau-Ponty 1995, p. 269-270).

O corpo estesiológico é a natural consecução desse périplo pela "evolução do conceito de Natureza" (1995, p. 265). Por seu intermédio realiza-se a "Einfühlung do corpo com o ser percebido e com os outros corpos" (1995, p. 272), relação de ser (como o é toda percepção) e não de conhecimento. Com o que concluir pelo simbolismo do corpo, por seu poder de ser alhures e, nesse movimento que é o do sentir, encontrar "um Logos do mundo natural, estético, sobre o qual se apóia o Logos da linguagem" (1995, p. 274).

Matéria a ser desenvolvida - "em particular por aprofundamento da línguagem e da história” (1995, p. 275) -, preconizava o projeto inacabado do último Merleau-Ponty. O discurso mantém-se aqui no tom interrogativo:

o corpo humano é simbolismo [...] Mas é mais que uma metáfora ? Pode o simbolismo da linguagem esclarecer o corpo ? Não é ele outra coisa ? Simbolismo de indivisão, sentido latente e simbolismo convencional, sentido manifesto (Merleau-Ponty 1995, p. 281-282).

Razão porque o extenso estudo sobre a Natureza conduzido por Merleau-Ponty em seus cursos no Collège de France culmina na análise da estrutura estesiológica do corpo humano, cuja "natureza dupla" explica como "o mundo e os outros se tornam nossa carne" (1995, p. 273). Tomar o corpo como simbolismo - e, reciprocamente, a linguagem como "segundo corpo" e "corpo aberto" - é modo de esclarecer o enigma de uma corporeidade indistintamente aberta e fechada, interna e externa, coisa e mensurante de todas as coisas. A operação exige, contudo, que se avance para além da Auffassung als ("consideração de algo como") pois que, lembra Merleau-Ponty, na distinção entre significante e significado o corpo é sempre o grande esquecido. 
Dizendo que o corpo é simbolismo, quer-se dizer que, sem Auffassung prévia do significante e do significado supostamente separados, o corpo passa no mundo e o mundo passa no corpo: o sentir ou o prazer, porque o corpo é móvel, isto é, poder de estar alhures, são desvelamento de algo. Um órgão do sentido móvel (o olho, a mão) é já uma linguagem, pois é uma interrogação (movimento) e uma resposta (percepção como Erfühlung/realização de um projeto), falar e compreender. É uma linguagem tácita [...] (Merleau-Ponty 1995, p. 273).

O tácito, modo pelo qual "a palavra pronunciada ou compreendida antecipa seus próprios motivos” (1995, p. 274), é razão para reivindicar um simbolismo natural do corpo sem ter de convocar um sujeito pensante e suas convenções. Haveria um Logos do mundo natural sobre o qual se apoiaria o Logos da linguagem. Seu esclarecimento, insiste Merleau-Ponty, é tarefa central para uma filosofia que, empenhada em iluminar as indistinções entre natureza física, vida e espírito, visa suplantar o pensamento causal-realista e o idealismo filósofico para encontrar no Ser bruto, selvagem, vertical uma dimensão outra que não aquela da representação ou do Em si (cf. 1995, p. 275). Dimensão a precisar, como se disse, em particular pelo aprofundamento da linguagem e da história. Sabe-se como esse aprofundamento, no processo que move contra a causalidade como produção de ser por investimento no local e no instante, propõe passar do espaço projetivo ao espaço "de que nós somos feitos", onde procurar não mais por detrás, mas por entre os elementos.

\section{Referências}

ALLIEZ, E, A assinatura do mundo. O que é a filosofia de Deleuze e Guattari. Rio de Janeiro: Editora 34, 1995.

BARBARAS, R. "Merleau-Ponty et la nature". Disponível em http://www.ac- toulouse.fr/philosophie/forma/barbaras.htm.

DELEUZE, G. Qu'est-ce que la philosophie? Paris: Minuit, 1991.

GARELLI, J. Rythmes et mondes. Au revers de l'identité et de l'altérité. Grenoble: Jérôme Millon, 1991.

MERLEAU-PONTY, M. La Nature. Notes de cours du Collège de France. Paris: Seuil, 1995.

—. Phénoménologie de la perception. Paris: Gallimard, 1945.

Signes. Paris: Gallimard, Paris, 1960

. Le visible et l'invisible, Paris: Gallimard, 1964

L'oeil et l'esprit. Paris: Gallimard, 1964 (1964a).

. Résumés de cours. Collège de France 1952-1960. Paris: Gallimard, 1968.

Notes des cours 1959-1961. Paris: Gallimard, 1996.

PATOCKA, J. Papiers phénoménologiques. Grenoble: Jérôme Millon, 1995.

SIMONDON, G. L'individu et as gênese phsyco-biologique. Grenoble: Jérôme Millon, 1995.

. Du mode d'existence des objets techniques. Paris: Aubier, 1989. 